\title{
Nacionalizar y educar: problemas de la Educación Común en los Territorios Nacionales \\ (1890-1940)
}

\section{To nationalize and to educate: problems of common education in the National Territories \\ (1890-1940)}

\author{
Adrián Cammarota \\ Universidad Nacional de la Matanza \\ (Argentina) \\ adriancammarota2000@gmail.com
}

Recibido: 11-02-2019

Aceptado: 10-05-2019

Publicado: 05-06-2020

\section{Resumen}

El trabajo tiene por objetivo analizar la educación primaria en los Territorios Nacionales entre 1890 y 1940 en la Argentina. Desde una perspectiva tributaria de la historia social, se abreva en un conjunto de nudos problemáticos que tuvo la repartición central para llevar adelante la gesta educativa, a saber: el rol de las comunidades locales en las demandas para la creación de escuelas, las condiciones materiales de los edificios, las limitaciones presupuestarias, la cuestión de la "nacionalización" de las comunidades indígenas y, por último, la fiscalización de las escuelas particulares extranjeras.

Palabras Clave: educación, territorios nacionales, nacionalismo, demandas comunidades locales 


\begin{abstract}
The objective of the work is to analyze primary education in the National Territories between 1890 and 1940. From a social history starting point, weaddress a set of problematic knots that central power had to carry out the educational venture, namely: the role of local communities in the demands for the creation of schools, the material conditions of buildings, budgetary limitations, the question of the "nationalization" of indigenous communities and, finally, the control of foreign prívate schools.
\end{abstract}

Keywords: education, National Territories, nationalism, demands, local communities

$$
\propto \tilde{e} \propto
$$

\section{Introducción}

La avanzada civilizatoria presente en el proyecto de Sarmiento y esbozada por la elite dirigente, se extendió por los vasos comunicantes del territorio, amalgamando propuestas pedagógicas e incentivos de modernización sobre espacios culturales circunscriptos a tradiciones, formatos y estructuras consideradas pre-modernas. Sobre este escenario, la escuela en los Territorios Nacionales consumó las aspiraciones del Estado nacional en relación al desarrollo de la infancia, la nacionalidad y la soberanía territorial. Este trabajo tiene por objetivo analizar y trazar un mapa exploratorio sobre la escolaridad primaria en los Territorios Nacionales dando cuenta de los mecanismos de intervención aplicados por el Consejo $\mathrm{Na}$ cional de Educación (en adelante, $\mathrm{CNE}$ ) para expandir la escuela pública, bajo la égida de la Ley de Educación Común (1420) entre los años de 1890 y 1940.

Desde una perspectiva tributaria de la historia social, el trabajo inquiere en los siguientes nudos problemáticos: la creación de escuelas y las condiciones materiales de los edificios, las limitaciones presupuestarias del CNE, el pro- blema de la "nacionalización" en las escuelas rurales y la fiscalización de las escuelas privadas en manos de las comunidades extranjeras. En líneas generales, las preguntas que guían la investigación son las siguientes: ¿cómo se imbricaban las demandas locales con el poder central? ¿Qué rol cumplían los funcionarios del CNE en la expansión de la escolaridad en los Territorios? ¿Cuáles eran los mecanismos normativos para la creación de las escuelas? ¿Qué obstáculos encontraron los maestros en relación a las comunidades locales para sostener el ideal de la Ley 1420? ¿Qué problema representaban las escuelas particulares en manos de comunidades extranjeras? Cabe señalar que siendo una investigación exploratoria, apuntamos a señalar algunas de las problemáticas subyacentes en los interrogantes mediantes casos puntuales rescatados del Archivo Intermedio de la Nación (en adelante, AIN). Lejos está la pesquisa de plantear una generalidad para un espacio geográfico tan amplio.

El recorte temporal comprende la génesis de la Inspección de Escuelas Primarias en los Territorios y Colonias Federales en 1890 y las primeras cuatro décadas del siglo XX, momento 
en el cual la normativa para la expansión de la escolaridad en los Territorios se consolidó haciéndose visibles los diagnósticos, las propuestas e interpelaciones de los actores involucrados.

Los estudios sobre la escuela rural y territorios marginales han captado la atención de los investigadores en América Latina (Soto Arango, 2012; Vaughan, 2001). En Argentina, se ha avanzado en los problemas por los cuales atravesó la escuela rural en la región Pampeana desde el campo de la salud, los registros demográficos y la tabulación de información censal (Di Liscia, 2009), o el debate sobre el curso curricular que asumió la escuela rural entre el modelo alfabetizador o el paradigma utilitario (Ascolani, 2012).

Las pesquisas sobre las relaciones políticas entre el poder central y los Territorios Nacionales alertaron sobre las pretensiones centralistas y las limitaciones en la ciudadanía política de los habitantes de estos espacios (Ruffini, 2004). El análisis fue encarado desde la historia política ya que el ordenamiento de los Territorios Nacionales formó parte del proceso constitutivo del Estado. Estos estudios resultan vitales para examinar la función que jugaba la escuela en un escenario en donde el Estado Nacional tenía atribuciones para organizar la actividad política y educativa, ejercer el control social y proyectar los principios de la nacionalidad (Varela, 2015).

El trabajo tiene un enfoque analítico-descriptivo poniendo de manifiesto determinados mecanismos que organizaron la escuela en los Territorios Nacionales. Por lo tanto, el artículo se apoya en un conjunto de expedientes que forman parte del acopio documental del CNE atesorados en el AIN, estadísticas censales y los informes de maestros publicados en $E l$ Monitor de la Educación Común (en adelante, $E M E C$ ). Seleccionamos aquellos expedientes que daban cuenta de las demandas de los vecinos de los Territorios para la creación de escuelas ya que nos permiten vislumbrar una serie de nudos problemáticos que analizamos en el corpus del trabajo y que fueron señalados al comienzo del artículo. Para ello en la primera sección desarrollamos las estadísticas de la población escolar en los Territorios, la incipiente legislación para la extensión de la escuela pública y el surgimiento de la Inspección de Escuelas Primarias en los Territorios y Colonias Federales cargo de Raúl Díaz. Luego pasamos a estudiar la participación de la sociedad civil en la gestación de las escuelas territoriales y el entramado normativo para la aprobación de dichos edificios. Nuestro objetivo es interpretar los mecanismos, interpelaciones y demandas que motorizaron la creación de las instituciones educativas.

En la segunda parte, reflexionamos sobre los avatares de los maestros en el ejercicio de la docencia en relación con el medio geográfico en los Territorios, las comunidades locales y los sentidos esbozados en sus informes al CNE. Por último, señalamos un caso relacionado con el funcionamiento de cuatro escuelas en $\mathrm{La}$ Pampa gestionadas por una comunidad alemana. El tema en cuestión expresaba la preocupación de la burocracia educativa en torno a las escuelas particulares y a la idea de la "extranjerización” de la educación.

\section{Territorios Nacionales, legislación y población escolar}

La escuela en los Territorios Nacionales consumó las intenciones y los proyectos del 
Estado Nacional entroncados con la infancia, la nacionalidad y la soberanía territorial. Justamente, los Territorios fueron unidades administrativas centralizadas cuyo objetivo eran consumar la expansión territorial luego de la sanción de la Constitución en 1853, delinear y controlar los territorios en disputa con los países limítrofes y fiscalizar a las comunidades indígenas que poblaban el terruño. Creados en 1884, abarcaban las actuales provincias de Chaco, Chubut, Formosa, La Pampa, Misiones, Neuquén, Río Negro, Santa Cruz y Tierra del Fuego. Entre 1951-1955, durante el gobierno de Juan Domingo Perón, los territorios fueron provincializados, exceptuando Tierra del Fuego que se convirtió en provincia recién en 1990.

La creación de los Territorios fue precedida por la génesis del CNE en 1881. En sus inicios tuvo jurisdicción sobre la Capital Federal, los Territorios Nacionales y las Colonias. Sobre este amplio espacio geográfico se aplicó la ley de Educación Común que estructuró el sistema educativo a nivel nacional. La instalación de escuelas, ya sea en las colonias o pueblos de los Territorios, estaba contemplada en la Ley 1420. Por ejemplo, el artículo 6 denominaba escuela rural al establecimiento ubicado en la campaña, lejos de los centros urbanos o suburbanos. A partir de 1902, se empezó a utilizar el término de escuelas rurales. Al hablar de los territorios o "lo territoriano" nos referimos a tres variables específicas señaladas por la historiografía: una dimensión espacial, es decir, los entes diferenciados en la estructura jurídica del Estado; un momento en el devenir y, por último, a la identidad, en donde la pertenencia a los Territorios Nacionales se definía sobre una base espacial que suponía el manejo diferencial de los derechos políticos (Bucciarelli y Jensen, 2008). La Ley de Educación Común se ex- tendió sobre las provincias gracias a la sanción de la Ley Laínez (1905). Esto le permitió al $\mathrm{CNE}$ crear escuelas en aquellas provincias que lo solicitasen, esencialmente, por la falta de recursos. Así la repartición central se transformó en una organización de alcance nacional, con una estructura centralizada y con un equipo de funcionarios que respondían de manera vertical a las directivas de las autoridades estatales. La escuela pública, en todo el territorio del país, era parte de un sistema que intentó forjar al buen republicano, inculcando valores cívicos y morales. En este sentido, más que una función económica, la escuela cumplió una función política en pos de alcanzar el sentimiento de argentinidad (Lionetti, 2005).

En 1902 se reglamentó la subvención escolar para la construcción de escuelas de los Territorios Nacionales. También se decretó la exoneración de impuestos para las asociaciones cuyas escuelas tuvieran por finalidad otorgar instrucción y educación gratuita al mayor número de niños y niñas pobres, sin distinción de nacionalidad y credo. La excepción del impuesto territorial se aplicó a las propiedades de renta donde funcionaban las escuelas, a la construcción de edificios escolares, a la adquisición de muebles y libros y la asistencia médica que incluía medicamentos y alimentos durante la enfermedad del escolar.

Una de las necesidades de la organización del sistema escolar en los Territorios era la elaboración de estadísticas "probas". La tabulación de información confiable a fines del siglo XIX se interponía como uno de los impedimentos para la organización estatal. La Oficina de Estadística Nacional, que funcionó entre 1864 a 1875 y dependió del Ministerio del Interior, se encargó en ese período de la recolección de información. 
Con la creación de los registros civiles en los territorios y en las provincias el Estado se aseguró el control de la información. Sin embargo, las dificultades para el relevamiento demográfico no desaparecieron e intentaron superarse gracias a la aplicación de normativas específicas y la recolección de información a partir de la incipiente burocracia de los Territorios Nacionales, es decir, policías y maestros (Di Liscia, 2009, p. 271). Desde fines del siglo XIX, el CNE promovió los censos escolares, a pesar de que su elaboración constituía un problema por las dificultades en el relevamiento de datos. Por resolución del 24 de enero de 1907 el CNE encargó a los directores de escuelas el levantamiento anual del censo de la población en un radio prudente de la escuela.

Al hablar de la población en los Territorios Nacionales en las primeras cuatro décadas del siglo $\mathrm{XX}$, nos referimos a una población eminentemente rural sobre un extenso espacio geográfico y con una población diseminada. A pesar de la fragmentación de los datos estadísticos, podemos darnos una idea de la población escolar en los Territorios gracias al trabajo de Jorge Meneclier, quien realizó un estudio en el año 1920, tomando como base el censo de 1914 y cuyos datos se encuentran expresados en la Tabla 1.

Según los datos que se desprenden del estudio, se puede estimar que hacia 1920 , cerca de 82.000 niños/as de 6 a 14 años estaban en edad escolar y 40.000 de ellos concurrían a las escuelas para formarse. Sin embargo, un gran porcentaje de ellos eran varones ya
Tabla 1. Población escolar en los

Territorios Nacionales (1914-1914)

\begin{tabular}{llll}
\hline TERRITORIO & $\begin{array}{l}\text { Superficie en } \\
\mathrm{Km}^{2}\end{array}$ & $\begin{array}{l}\text { Población } \\
\text { Escolar en } \\
1920\end{array}$ & $\begin{array}{l}\text { Niños/as } \\
\text { por km }\end{array}$ \\
& & & \\
\hline
\end{tabular}

\begin{tabular}{llcl}
\hline Chaco & $98.238 .279,00$ & 11.718 & 0,1193 \\
Chubut & 225.722 .564 & 5379 & 0,0239 \\
\hline Formosa & 75.480 .040 & 4689 & 0,0621 \\
La Pampa & 144.183 .363 & 27.560 & 0,1912 \\
\hline Los Andes & 72.755 .055 & 661 & 0,0091 \\
Misiones & 30.430 .520 & 0 & 0,4715 \\
\hline Neuquén & 96.464 .474 & 7669 & 0,0795 \\
Río Negro & 201.009 .689 & 10413 & 0,0518 \\
Santa Cruz & 243.336 .350 & 1582 & 0,0066 \\
Tierra del Fuego & 21.610 .000 & 215 & 0,0099 \\
\hline Totales & $\mathbf{1 . 2 0 9 . 2 3 0 . 3 3 4}$ & $\mathbf{8 4 . 2 3 3}$ & $\mathbf{0 , 0 6 9 6}$ \\
\hline
\end{tabular}

Fuente: Meneclier (1920, p. 79)

que las niñas estaban destinadas a las tareas domésticas (Meneclier, 1920, p. 82).

En el Censo Escolar de 1931, que se llevó a cabo con escasez de recursos y solo arrojó cifras globales y parciales, se desprende que la población escolar en los Territorios había ascendido a168.588 niños/as, cifra que resulta un tanto engañosa ya que no guardaba relación con la población total de los Territorios que en ese año se calculaba en 570.000 habitantes. Con respecto a los maestros/as, en 1919 el total ascendía 1.345, en 1929 la cifra trepó a 3.458 y en 1939 llegaban a 5.867. Para realizar estos cálculos el CNE se valió de apreciaciones empíricas y estimaciones sobre la general hechas en base al crecimiento vegetativo a partir del Censo General de 1914. También 
los funcionarios tomaron los registros locales realizados por los maestros, los registros de inscripción y datos suministrados por las oficinas enroladoras. ${ }^{1}$

Los datos aportados por los Censos fueron señeros ya que alertaban sobre las posibilidades, recursos y políticas para incorporar a los miles de niños nacionales y extranjeros al sistema escolar. Asimismo, la densidad poblacional echaba luz a uno de los obstáculos más recurrentes en las escuelas de los Territorios: la dispersión de la población y las distancias que debían recorrer a caballo o a pie, niños/as de 6 o 7 años de edad. Como veremos más adelante, en los relatos o memorias de los maestros, este obstáculo fue cardinal durante toda la mitad del siglo XX. A esto había que sumarle, según los registros oficiales, la apatía de los padres, el juego, el alcoholismo, la pobreza, los caminos pésimos, la incomodidad de los locales escolares y la diseminación de la población (CNE, 1938, p.151).

Teniendo en cuenta este escenario, y ante la necesidad de fiscalizar esos territorios, el primer paso fue edificar una estructura burocrática que permitiera llegar a los lugares más recónditos del espacio nacional.

\section{Raúl Díaz \\ y la Inspección de Escuelas Primarias en los Territorios y Colonias Federales}

A fin de tener una mayor presencia en los Territorios, el presidente del CNE, Benjamín Zorrilla, creó la figura del Inspector Especial

1.E1 Censo Escolar en los Territorios. Disertaciones por Radiofonía.(1940). El Monitor de la Educación Común (EMEC), 60(815), pp. 59-67. Biblioteca Nacional del Maestro (BNM). de Escuelas de Colonias en 1890. La decisión del Poder Ejecutivo se sustentó en un informe realizó por el Inspector de Escuelas de Capital Federal, Carlos Vergara, quien realizó un viaje de inspección por el norte del país (Misiones, Formosa y Chaco). Así las cosas, en 1890, nació la Inspección de Escuelas Primarias en los Territorios y Colonias Federales, designando como inspector a Raúl B. Díaz. Esta inspección tenía a su disposición un cuerpo de funcionarios que periódicamente elevaban los informas al CNE sobre la marcha de la educación en los Territorios y Provincias. Los informes eran editorializados en el órgano de difusión del CNE: El Monitor de la Educación Común.

Díaz fue inspector entre 1890 a 1916. Sus prolíferos reportes guiaron la política del CNE en los Territorios Nacionales y Colonias. Los informes, observaciones y ensayos de Díaz brindaran al CNE un diagnóstico elocuente sobre la situación de la educación, los alcances y límites de la ley 1420. En este sentido, uno de los problemas acuciantes para Díaz era la edificación escolar. En 1907 la describía como un "problema sin solución": de un total de 200 escuelas solo había 35 edificios fiscales, muchos de los cuales estaban en condiciones paupérrimas. Por añadidura, el servicio de provisión de útiles, muebles y textos a la escuela ha sido tardío e intermitente. ${ }^{2}$ En sus viajes el funcionario se había topado con ranchos sin pavimentos; tanto en el norte como en el sur del territorio, por lo que la escuela era vista como el vehículo de contagio para todas las infecciones o enfermedades.

2. Díaz, R. (1907). Informe del Inspector General de los Territorios Nacionales sobre los progresos realizados en los mismos, relacionados con la Instrucción primaria en año 1906. EMEC, 27(413), p. 420. 
Según Díaz, para que la escuela sea exitosa debía atraer y retener en la profesión a una clase superior de educadores ya que la vida de los maestros en los Territorios Nacionales y Colonias transcurría en condiciones duras. Los funcionarios del CNE habían observado tempranamente a fines del siglo $\mathrm{XIX}$, las consecuencias pedagógicas de los condicionamientos del medio. Los maestros titulados escaseaban dejando a las escuelas territoriales en manos de maestros sin preparación alguna, según la observación del Díaz.

El funcionario también pugnaba por aumentar los nombramientos de nuevos inspectores de sección. En 1909, de 47 escuelas existentes en Formosa, Chaco Austral y los Andes, 14 correspondían a la región Noroeste y las 33 restantes se hallaban en el litoral de Chaco y Formosa. En número de escuelas de la Pampa Central era de 65, esparcidas por tres zonas delineadas por las colonias Mitre y los Puelches, atravesadas por el Atuel, Salado y Curaco, hasta el límite con la provincia de Buenos Aires. ${ }^{3}$

La tarea de Díaz no se limitó a la gestión. Diseñó los programas para las escuelas de los Territorios Nacionales que en sus inicios tenían como modelo los programas sancionados en 1884 para la Capital Federal. Propuso modificar los programas introduciendo nociones de geometría aplicada, agricultura, contenidos de utilidad para los espacios rurales. En 1905 presentó un proyecto para aplicar nuevos programas que fueron aprobados por la Comisión Didáctica del CNE, denominado "Plan de Estudios

3. Díaz, R. (1909). Presupuesto escolar de los Territorios: deberes del Parlamento. EMEC, 28(441), p. 648. y Direcciones Complementarias para las escuelas rurales y de adultos de los Territorios y Colonias Nacionales", cuyo mentor fue el propio Díaz. ${ }^{4}$

Por último, Díaz vislumbró tempranamente el rol de las comunidades locales como rueda de auxilio del Estado en la gesta educativa y uno de los puntos cardinales en la radicación de la escuela en los parajes más alejados donde convergían la acción popular y la oficial, con sociedades vecinales protectoras de la infancia. ${ }^{5}$

Como veremos a continuación uno de los puntales de la aplicación de la Ley 1420 fue la intervención de los vecinos, sociedades vecinales en la demanda y construcción de los edificios escolares.

\section{Los vecinos en la gestación de las escuelas en los Territorios Nacionales}

A pesar de las limitaciones en cuanto a la ciudadanía política en los Territorios, tanto la fundación de escuelas como la gestación de obras públicas, fueron viabilizadas gracias a la interpelación de las comunidades locales al poder político municipal y al poder central. Más allá de las demandas, el gobierno nacional impulsó cambios incipientes en los Territorios como el Plan de Fomento del Ministerio de Agricultura (1906-1907), bajo la presidencia de Figueroa Alcorta y el plan de Obras Públicas (1907-1913). En 1912 el Ministerio del Interior creó la Dirección General de Territorios Nacionales a cargo del jurista Isidoro Ruiz Moreno (Varela, 2015, p. 81) Sin embargo,

4.Para un análisis de la labor de Díaz ver: Fiorucci, 2015.

5. Díaz, 1907, p. 423. 
fueron los inspectores en los Territorios $\mathrm{Na}^{-}$ cionales y Colonias los que lograron llevar a los rincones más alejados los designios de la ley 1420 (Teobaldo, 2011).

Sin embargo, en la expansión de los servicios educativos jugaron un rol destacado las sociedades vecinales y las más sofisticadas Sociedades Populares de Educación. Diversas entidades sin fines de lucro vieron su génesis a fines del siglo XIX y principios del XX con la misión de expandir la escuela pública en el territorio nacional y buscar soluciones al problema de la infancia. El artículo 57 de la Ley de Educación Común establecía, en su apartado 18, que el CNE debía promover y auxiliar la formación de bibliotecas populares $\mathrm{y}$ maestros, al igual que las asociaciones $\mathrm{y}$ publicaciones cooperativas de la educación común.

Las Sociedades Populares de Educación fueron uno de los medios de propender la educación común en Capital Federal, Provincias y Territorios. El Primer Congreso Nacional de Sociedades se realizó en Buenos Aires en 1909 bajo los auspicios de la Asociación Nacional del Profesorado. Al calor de este clima, las sociedades se expandieron con diversos formatos. Algunas, gestadas en Buenos Aires, amplificaron sus recursos al resto del país. Así, el 19 de octubre de 1914, reunido en pleno el Primer Congreso Nacional del Niño, se declaró constituida la Liga Nacional de Educación (Liga Nacional, 1914).

Un ejemplo del funcionamiento lo encontramos en Colonia Lagos (La Pampa) en donde el vecino Armando Biaggetti, en representación de la Sociedad Popular "Unión y Fuerza" que él mismo presidía; se dirigió al Inspector Seccional para la creación de una escuela en dicha colonia debido a que el núcleo de niños analfabetos ascendía a más de setenta. La Sociedad de Colonia Lagos recolectó recursos por medio de donaciones en la que aportaron los vecinos y la gobernación del Territorio. $\mathrm{La}$ iniciativa fue aprobada por el CNE confluyendo en un movimiento societario que congregó a la comunidad en una campaña de donaciones para acondicionar el local donde funcionaría la escuela. Los donantes fueron listados por la Sociedad de Fomento "Unión y Fuerza" logrando acopiar un fondo de $\$ 574$. 70 moneda nacional, que fueron utilizados para construir el edificio. ${ }^{6}$ (Fotografía 1 y 2). Estos pedidos se multiplicaron particularmente en el Territorio de La Pampa desde su creación en 1891. No solo a través de los diarios de la zona, sino también ante las autoridades nacionales mediante los informes de Inspección y las Memorias de los Gobernadores. La sociedad mostraba su disconformidad considerando que eran insuficientes los servicios educativos para atender a las demandas de una sociedad en crecimiento. En las zonas rurales, el número de escuelas se había incrementado lentamente (Billorou, 2015, p. 205).

A fines del siglo XIX, las burocracias expertas tanto en el campo de la educación como en el campo de la salud pública; comenzaron a colonizar la estructura del Estado. Estas burocracias tendieron a ser austeras y eficientes en el manejo de los fondos públicos. Fundaron sistemas de control y administración que para intentar asegurar ambos servicios (Salvatore, 2016). Un claro ejemplo de ello fue la legislación que subvencionaba la instrucción primaria en las provincias y Territorios, los pedidos

6. Pedido de la asociación vecinal "Unión y Fuerza". Colonia Lagos, 5 de marzo de 1935. Caja 11. Fondo Consejo Nacional de Educación (FCNE). Archivo Intermedio de la Nación (AIN) 
Fotografía 1. Lista de donantes de la Sociedad de Fomento "Unión y Fuerza”, 1935.

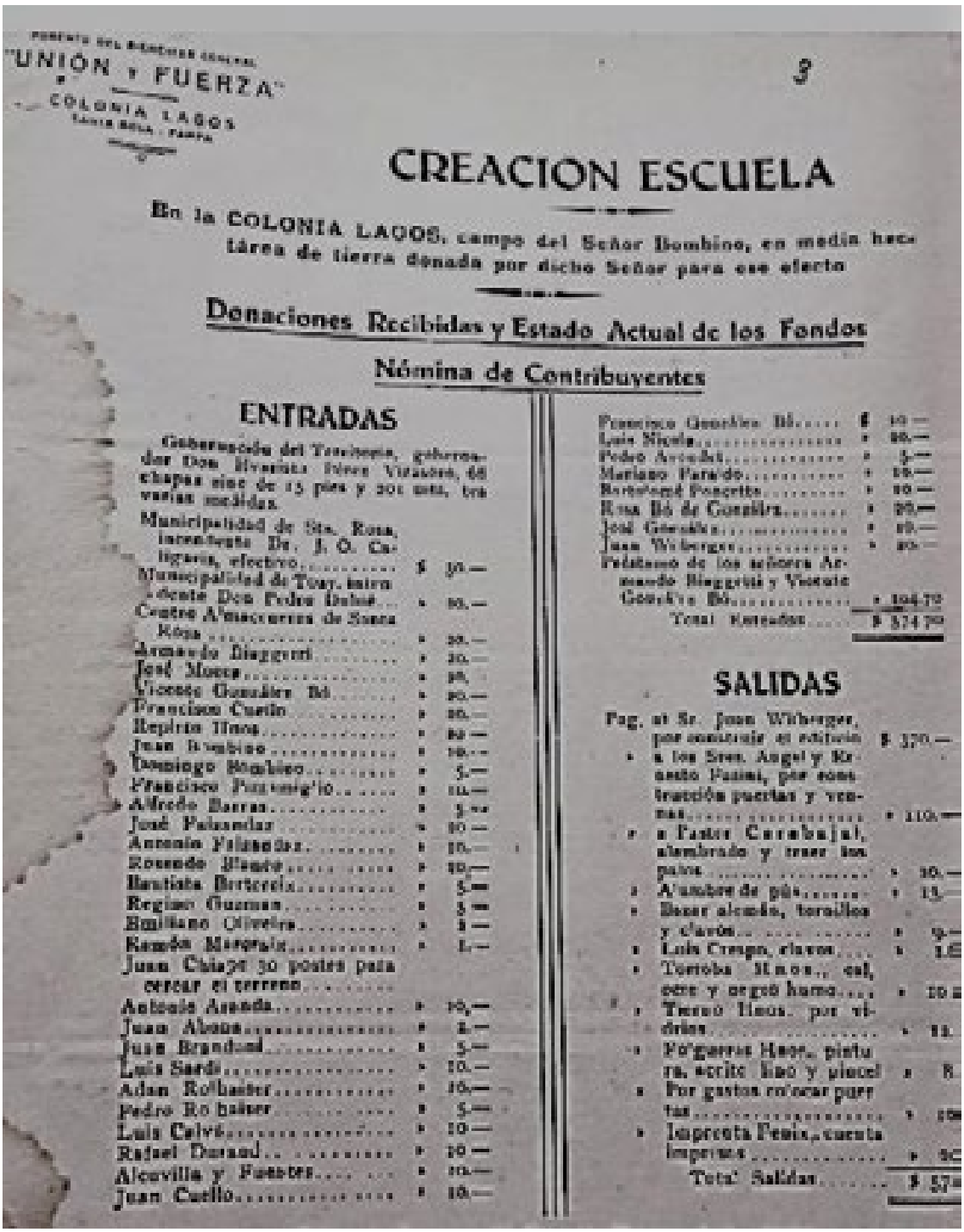

Fuente: Caja 11. Fondo Consejo Nacional de Educación (FCNE), Archivo Intermedio de la Nación (AIN), Buenos Aires. 
Fotografía 2. Convocatoria a evento cultural para recaudar fondos para la Sociedad de Fomento "Unión y Fuerza”, 1935.

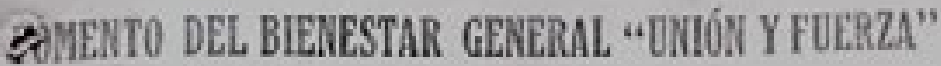

- colonir lagos - santa mosa, pampa

Col. Laggos, (S. Rosa), marzo 5 de 1935.

Sr.

A los efectos de reorganizar la Sociedad "union y FUERzA". ч olegir nuevas autoridades invitamos a ud. a la raunión que tendrá lugat el dia Domingo 12. a las 24 hs., en el local de la Escuela.

Además se tratarán asuntos ralacionados con la terminación de mejoras en la Escuela y todo lo concerniente al Art. 6* de nuestro reglamento.

Con tal molivo Saludo a Ud.

UICENTE GONZALEZ BO

ARMANDO BIAGGETT

Preibleale Sectetario

notA: La elección de la nuesa comleiden se harí por volación secrela.

Fuente: Caja 11. FCNE, AIN. 
de libros, útiles y demás. El CNE aportaba en conformidad con la ley de presupuesto y de acuerdo al artículo 1, hasta el 50\% del valor del terreno, hasta el $60 \%$ del valor de cada salón de enseñanza; hasta el 50\% del valor de cada pieza para las demás dependencias escolares. Esta suma se extendía hasta el $60 \%$ del valor del grupo del aljibe o pozo con molino, excusado y cercado del terreno, hasta el $40 \%$ del valor de la vivienda del director. El mayor gasto sobre estas contribuciones que demandaba la terminación total del edificio, quedaba por cuenta del vecindario. En cuanto a la Comisión de Vecinos, debía ser de cinco a siete miembros y estaban obligados a presentar ante la Inspección Seccional, una serie de referencias en relación a la escuela que se pretendía construir: descripción del aporte (si comprendiese terreno o materiales), un croquis con la orientación distribución y medidas de la construcción y un presupuesto detallado de la construcción. ${ }^{7}$

Ahora bien, la disponibilidad de los vecinos para articular con el poder político nacional la creación de instituciones educativas invitaba a que el régimen de locación del edificio escolar estuviese regulado por el CNE. Ya sea en terrenos o edificios particulares, por secesión de su dueño o arrendamiento, la reglamentación vigente solicitaba la intervención de los funcionarios escolares en la fiscalización del procedimiento.

\section{Los edificios escolares}

Ante las donaciones de locales o arrendamientos, la Inspección General de Territorios enviaba un inspector para verificar las condiciones mínimas de habitabilidad del local

7. Acta de Sesión 80, 19 de septiembre de 1926. Caja 11. 1935. FCNE. AIN. $y$, en paralelo, realizaba un censo escolar. Los censos eran elaborados por los vecinos o por el inspector sobre una simple planilla donde se consignaba el nombre y apellido de los niños/as y su edad. Al acordar el inspector con el vecindario la creación de una escuela, previa constatación de que reuniera las condiciones mínimas, el funcionario elevaba el pedido de mobiliario y útiles. Sin embargo, las cooperadoras escolares y el concurso vecinal aportaron en muchos casos los útiles de trabajo, semillas y demás elementos materiales necesarios en la escolaridad de los niños/as.

Los locales en los Territorios en general eran cedidos por particulares quienes firmaban un contrato de locación, los concedían gratuitamente por una determinada cantidad de años o los cedían por siempre. El sistema de arrendamiento también podía generar escuelas "itinerantes", rompiendo con la continuidad pedagógica de los niños/as de los parajes más alejados. Básicamente, esta situación estaba dada por las decisiones individuales del propietario del local o la evaluación de costos realizada por el CNE. En 1935, el propietario de un local en Colonia Catriel (Viedma) escribía al CNE sobre la situación de la propiedad. Habiendo terminado el contrato con la repartición central a fines de 1934, estipulado en dos años y no habiendo realizado el CNE ningún tipo de mantenimiento como estaba pautado, el vecino reclamaba en lo sucesivo el cobro de un alquiler por el edificio con miras a efectuar las reparaciones por su cuenta. La Inspección General decidió trasladar a otra localidad donde se disponía de locales gratuito. ${ }^{8}$

8. Caja 54, Expediente 1208, 1935. FCNE. AIN. 
Los informes de los funcionarios y de las oficinas, eran concisos y claros, limitándose al objeto que los convocaba y evitando, por resolución del 4 de febrero de 1908, la diatriba y la polémica. Iba acompañado de un plano de la escuela y una serie de datos volcados en una planilla en los que se constataba las dimensiones de las piezas, las comodidades en general del inmueble (si tenía cocina, agua de pozo, aljibe, superficie de los patios y los materiales empleados en la construcción del edificio). Por último, el funcionario tenía que consignar minuciosamente las vías y medios que debía realizarse desde Buenos Aires hasta el destino, $\mathrm{y}$ las diferentes jornadas en ferrocarril, vapor, automóvil, caballo, o lugares de trasbordo.

Hay que señalar que los inspectores de los Territorios eran funcionarios particulares. Debido a que el CNE era una organización centralizada y capitalina materializaban la mirada de la repartición en una geografía nacional cuyos detalles medio ambientales escapaban al conocimiento in situ de la burocracia estatal forjada en la cosmopolita capital de la República. Formados en los valores del normalismo, estos funcionarios emularon el camino de otros expertos que desde fines del siglo XIX y la primera mitad del siglo XX, colonizaron el Estado brindando diagnósticos y diseñando políticas de intervención en la esfera pública.

\section{Los locales escolares en los Territorios Nacionales}

Los edificios ubicados tanto en la Capital Federal, las Provincias como en los Territorios se ajustaban, como mencionamos al principio del trabajo a la Ley 4874 y la Ley 1420. En la distribución de locales y locación o la adquisición de casas para escuelas, actuaba la Dirección General de Infraestructura y la Inspección Médica Escolar.

Para subsanar el problema de la edificación escolar, en 1918 se sancionó la ley 10.358 que le atribuía al CNE el $75 \%$ del impuesto a los boletos de entrada a los hipódromos. Este recurso estaba destinado exclusivamente a las construcciones escolares en la Capital Federal y Territorios Nacionales. Sin embargo, recién en 1932, quedó sancionada la ley 11.619 de edificación escolar en todo el país. Según el artículo 1, el Consejo estaba autorizado para contratar con particulares propietarios de inmuebles o con entidades privadas la construcción de escuelas o edificios para escuelas de la Capital, Provincias y Territorios nacionales (CNE, 1938, pp. 52-53).

A pesar de la profusa normativa que estructuró al incipiente sistema educativo a fines del siglo $\mathrm{XIX}$, las deficiencias de los locales escolares no fue solo una problemática de los territorios alejados: el escenario capitalino de Buenos Aires condensaba una serie de problemáticas que contradecían la idea de una pujante y moderna capital. Es decir, las realidades materiales e higiénicas de las escuelas de Capital Federal, en no pocas excepciones no diferían de las condiciones materiales de las escuelas de los Territorios y Colonias.

Muchas de las escuelas bajo jurisdicción del $\mathrm{CNE}$ no funcionaban en edificios propios y en las condiciones demandadas por la reglamentación. En Capital Federal, se recurría a las casas particulares para albergar a los niños/ as que no podían ser repartidos en las escuelas fiscales. $^{9}$

9. $\operatorname{EMEC~(1890).~9(177),~pp.~1161-1162.~}$ 
Fotografía 3. Edificio construido por los vecinos para la Escuela primaria núm. 189 en Colonia General Necochea (Chaco), 1934.

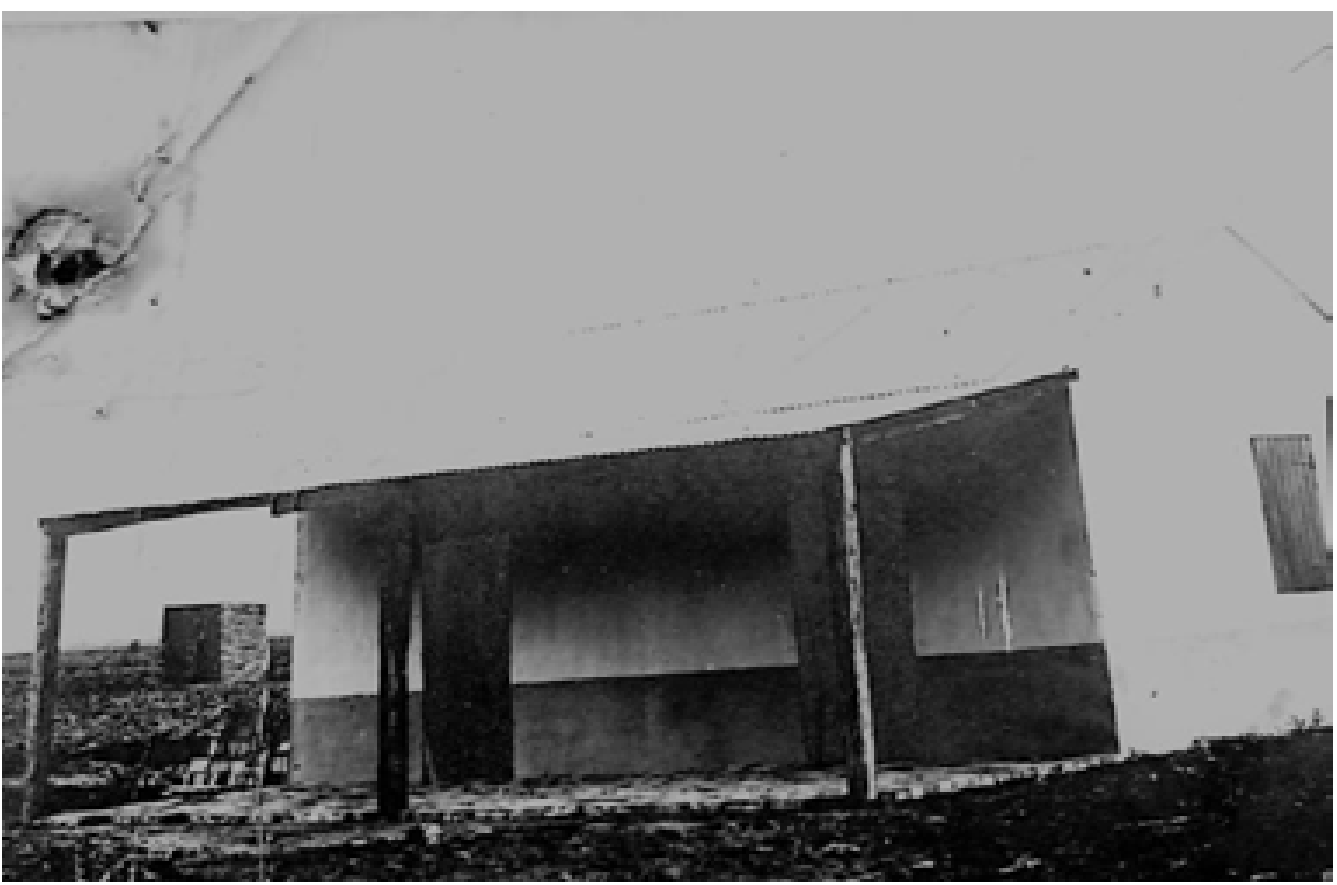

Fuente: Caja 1, FCNE, AIN.

En los Territorios el problema estaba más acentuado: diversos locales escolares levantados carecían de comodidades. Las construcciones realizadas por los vecinos o alquiladas a propietarios presentaban deficiencias de orden pedagógico, sin embargo, eran ocupadas ante la imposibilidad del CNE de destinar recursos apropiados.

Ahora bien, ¿qué discernimientos se utilizaban para la inspección de los locales públicos y privados en referencia a la higiene escolar y a la creación de los edificios? Cada local era estudiado según su orientación, sus condiciones higiénicas generales, la capacidad cúbica de sus salones de clases, la cantidad de aire y la superficie correspondiente a cada niño, entre otras cuestiones.

Como hemos señalado, la estricta normativa pareciera que regularmente era soslayada ante las limitaciones materiales de los Territorios y Colonias, y el ajustado presupuesto de los vecinos. Por añadidura se agregaba la imperiosa necesidad de escolarizar a la población infantil. La situación se agravaba si las variables económicas de locales se resentían ante las inclemencias del clima o la caída de los precios de los productos primarios como ocurrió en la Colonia General Necochea (Chaco) donde, a pesar de las dificultades económicas la $\mathrm{Coo}^{-}$ peradora Escolar erigió en el paraje la escuela 
Fotografía 4. Escuela General Justo José de Urquiza núm. 8, Clorinda, Formosa.

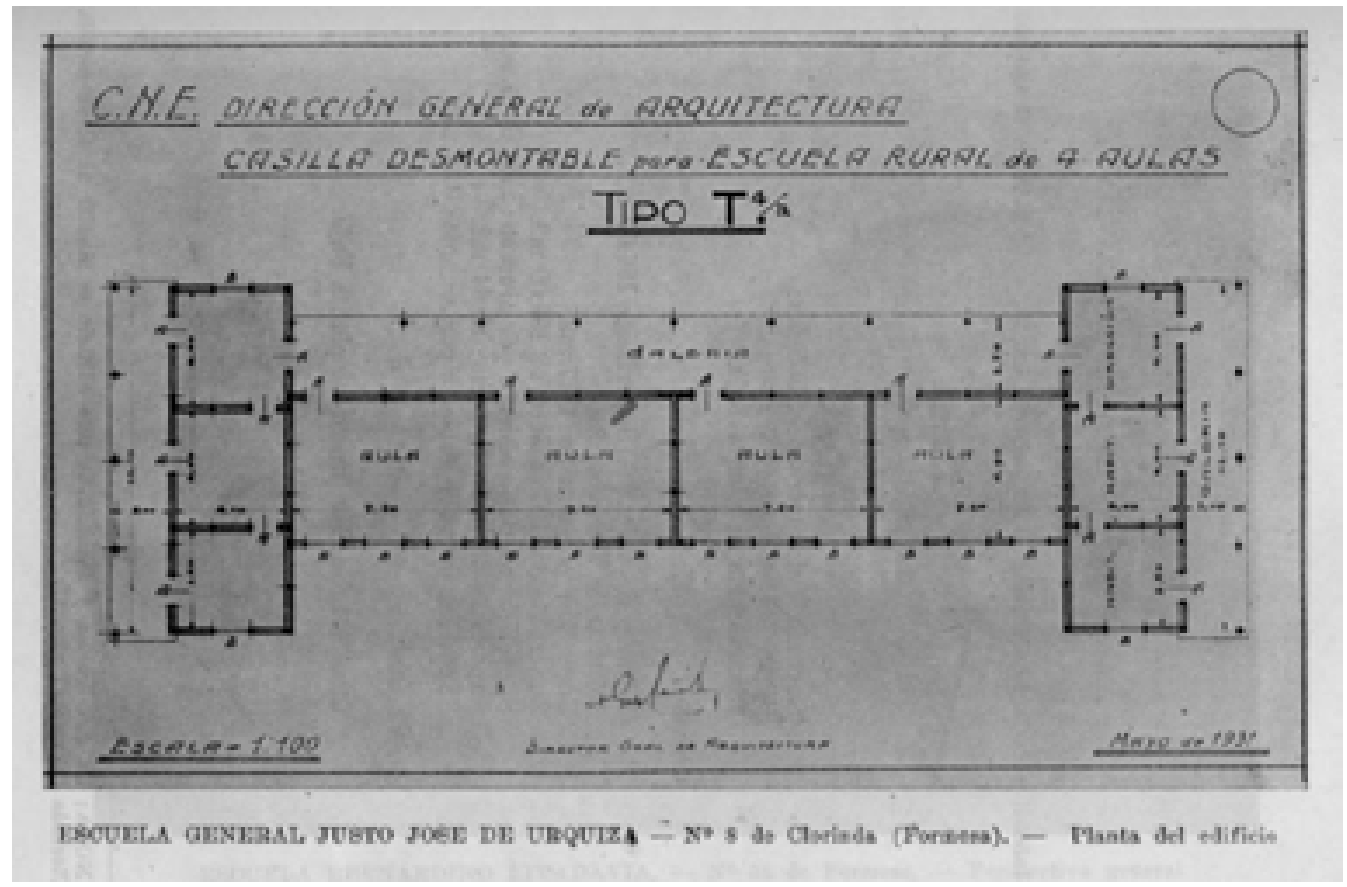

Fuente: CNE (1942, p. 49).

primaria núm. 189. El local constaba de un salón de $7 \mathrm{x} 4$, emplazado en un terreno de $75 \mathrm{~m}$ $x 75 \mathrm{~m}$, propiedad de un lugareño. ${ }^{10}$

La imagen de la escuela de Chaco, caracterizada por su precariedad, contrastaba con los edificios de las ciudades de los territorios, y las escuelas rurales fundadas en las primeras décadas del siglo XX, con amplios salones para dictar clases, patios de esparcimiento y cuyas comodidades y disposiciones cumplían con la reglamentación vigente. Algunas estaban diseñadas bajo el formato de construcción tipo $\mathrm{T}$

10. Caja 1, 1934. FCNE. AIN. como se ve en el plano (Fotografía 4) y techos de teja de estilo colonial (Fotografía 5).

En principio, hay que decir estos edificios debían contar con pocas aulas, un patio y la casa del director. Debido a que en las primeras décadas del siglo XX la escuela rural aún estaba lejos de alcanzar su objetivo primario -enseñar al alumno a mejorar las condiciones del trabajo rural-, la Dirección General de Arquitectura dependiente del CNE, consideró que cada escuela debía estar edificada en una superficie de una hectárea, con miras de atraer mayor matrícula escolar en un futuro (CNE, 1938). 
Fotografía 5. Escuela núm. 15, San Ignacio, Misiones.

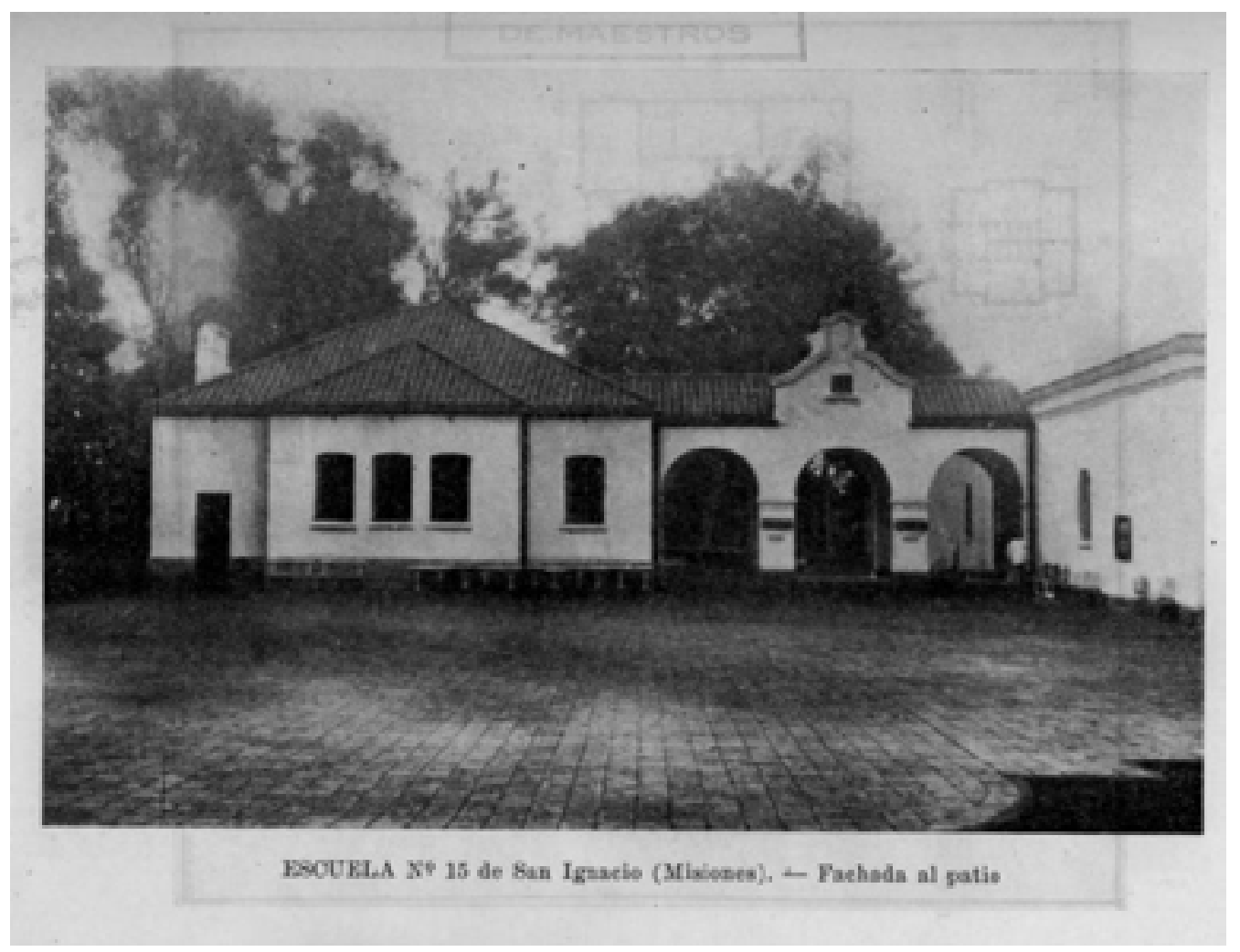

Fuente: CNE (1942, p. 63).

Veamos el caso del Territorio de Río Negro donde el ámbito educativo atravesó, desde la instalación de la primera escuela en 1879 , una serie de problemáticas denunciadas en la prensa local: las malas condiciones de los edificios, la inasistencia a clase o el bajo número de inscriptos. Hacia 1912 la población escolar había aumentado, sin embargo, la asistencia seguía siendo un problema. En el Valle inferior como en el Alto Valle rionegrino, la base económica era la actividad agrícola-ganadera. La inasistencia de los educandos se debía a que gran número de niños asistían a dichas actividades productivas. La mayoría de las veces, la obligación de escolarizar a los niños y niñas, dependió de la realidad social y económica de las familias (Zaidenwerg, 2013, pp. 212-214).

Las escuelas levantadas en la periferia de los Territorios merecieron dos denominaciones: "las escuelas de fronteras" y las de "situación desfavorable". Las escuelas de fronteras contaban de un taller para trabajos manuales y el personal directivo, docente y de servicio tenía 
que estar compuesto de argentinos nativos. Cerca de ellas las autoridades debían gestionar un Registro Civil, un Juzgado de Paz, Destacamento de Policía y estafetas de Correos

Subyacía una fina línea divisoria entre una y otra que en determinadas circunstancias generaban especulación. Por ejemplo, en febrero de 1935, el director de la escuela núm. 117 de Puerto Mineral, Misiones, solicitaba al Inspector General de Escuelas Juan D., que la escuela fuera considerada como "fronteriza" por estar situada frente a un pueblo paraguayo y a menos de 300 m del río Paraná. El 50 \% de los niños que concurrían a su escuela eran de dicha nacionalidad. La escuela, desde la óptica del director, cumplía una triple función: nacionalizaba, ilustraba y educaba. Sin embargo, la respuesta del visitador escolar, fue que la escuela merecía tal denominación pero que no le correspondía percibir sobresueldo pues estas escuelas no eran comparables con las denominadas de situación desfavorable. ${ }^{11}$

Como hemos visto, la ingeniería estatal para llevar la educación pública a los territorios más alejados implicaba concursar los recursos necesarios, y la intervención de los funcionarios que de forma intermediaban entre el activismo vecinal y los funcionarios del CNE. Cabe señalar que 1934 fue el Cincuentenario de la Educación Común, hecho que motivó un balance sobre la extensión y el funcionamiento de los servicios educativos. Los resultados, según el CNE, no eran los esperados. Las causas replicaban las mismas problemáticas señaladas al principio del trabajo: carencia de locales adecuados en los Territorios, la dispersión de

11.Pedido al Inspector General de Escuelas, Juan Deluiggi, 23 de marzo de 1935. Caja 11. CNE. AIN. las escuelas y la situación socio-económica de las familias.

No obstante, la misión civilizatoria no dependía solo de estas variables: las relaciones entre maestros y comunidades locales, como destinataria de las políticas educativas, sellaron la impronta de uno de los capítulos de esta trama que podía distar de las aspiraciones estatales.

\section{Maestros, educación rural y el "problema" indígena}

Las publicaciones dedicadas al magisterio enaltecían la valentía y el sacrificio de hombres y mujeres que se asentaban a los espacios más alejados del país con la misión del civilizar en los preceptos de la República. El maestro/a era una agente estatal cuya misión era recorrer hogares, divulgando la consolidación de la familia rural, combatiendo el nomadismo, pregonando el arraigo a la tierra, ilustrando sobre las dolencias endémicas y de las normas para enfrentarlas, moralizando y enseñando los beneficios de la Patria. El magisterio lentamente se fue feminizando a pesar de la oposición de algunos intelectuales (Fiorucci, 2016).

La realidad de los casos podía distar de las exaltaciones gubernamentales que esbozaban un arquetipo humano de maestro/a, reglado por el altruismo y el sacerdocio de la profesión. Sin embargo, no todos los maestros/as estaban convencidos de desarrollar su profesión en el ámbito rural de los Territorios Nacionales o de las provincias. Veamos un ejemplo: en 1921 el Poder Ejecutivo de la Provincia de Santa Fe concedió la autorización para instalar una escuela en Campo Arocena, distrito de Fuentes, Departamento de San Lorenzo. La seño- 
ra María Firpo de Arocena, ofreció por cinco años un local para 111 niños/as que recibirían instrucción. La escuela, a legua y media de la estación de Fuentes, rodeada de chacras de pequeña extensión trabajada por familia de colonos, y no había podido ofrecer "mayor halagos para decidir a ningún maestro a venir a establecerse aquí y dirigir" el establecimiento, según describe al CNE la señora Firpo. ${ }^{12}$

El diagnóstico realizado por el Inspector de Territorios Nacionales Raúl Díaz, a comienzos del siglo XX, señalaba la falta de maestros titulados frente al aula y su dudosa idoneidad. Estas opiniones se repitieron asiduamente durante la primera mitad del siglo XX. Maestros solo de nombre, se hacían cargo de la enseñanza primaria ante la falta de puestos cubiertos por docentes titulados. Ante esta situación, los extranjeros nacionalizados, pero quienes habían obtenido su título en el exterior, ofrecían sus servicios pedagógicos a las autoridades de turno.

Los informes de los inspectores enfatizaban sus juicios sobre la idoneidad de los maestros a cargo en las escuelas de los Territorios. En el año 1896 el subinspector de Territorios Nacionales, en su visita por la Pampa Central y Río Negro; señalaba que casi todas las escuelas estaban dirigidas por "maestros incompetentes" o "escasa preparación pedagógica" e instaladas en malos locales. ${ }^{13}$ Problemáticas del mismo calibre se repitieron en las primeras décadas del siglo XX. Incluso, hacia 1941, un funcionario observaba que si bien había maestros/as rurales, sus conocimientos sobre el campo eran muy limitados. La mayoría de los docentes recibidos en las escuelas normales rurales pre-

12. Caja 1, Expediente 1123, 1921. CNE. AIN.

13. $E M E C$ (1896).pp. 449-455. ferían desempeñar su trabajo en escuelas urbanas, gestionando la equiparación del título. ${ }^{14}$ Hay que señalar que las escuelas normales en el interior y en los pueblos no solo fueron pensadas como formadoras de maestros/as, sino también, como un instrumento para incorporar al interior a los preceptos de la modernidad. La presencia de la escuela normal fue estimable en la vida de los pueblos, ciudades pequeñas y medianas a principios del siglo $\mathrm{XX}$ (Fiorucci, 2011, p.139).

Una de las estrategias del CNE para motivar el desempeño docente en los Territorios fue aumentar, en 1920, la categoría de algunas escuelas conforme a los progresos escolares conseguidos por ellas, lo que suponía una mejora en el salario.

La vida solitaria del personal docente, allende a la montaña, a la selva o en la infinitud de la llanura desértica, desglosaban nudos de sentidos promovidos por el carácter sacralizado de la docencia. El maestro debía batallar contra la soledad del territorio, la indiferencia de determinadas comunidades locales a la "nacionalización” y a la escolarización, los sueldos paupérrimos y los padecimientos orgánicos de los niños/as. Con respecto a este último, un maestro que se había desemepeñado en una escuela de La Pampa señalaba, a fines de la década de 1930, que el raquitismo, las caries y la desnutrición se presentaban muy a menudo en las escuelas del interior. El maestro rural debía ser un ayudante sanitario del médico escolar con la habilidad para inyectar vacunas antitíficas, antigripales y antidiftéricas. En su caso, pidió asesoramiento al Departamento Nacional de Higiene y aprendió a aplicar la vacuna

14.Tarrago, E. (1946). El maestro rural. EMEC, 65(887/888), pp. 65-68. 
antivariólica inmunizando, según su testimonio, "a tres vecindarios de La Pampa contra la viruela". ${ }^{15}$

Las impresiones de los maestros mostraban las desventuras para la "nacionalización" de las comunidades rurales indígenas. Según un docente de Neuquén, las chozas construidas en los valles en las pendientes de las montañas, en límite con Chile, y la forma de vida regida por la satisfacción inmediata del sustento; tenía como protagonista al varón adulto y niño dificultando su escolarización, mientras que la niña vivía en la casa consagrada a la crianza de los más chicos. En verano, padre e hijo migraban a Chile. La "fiebre" patriótica se escurría en una escuela que, según la óptica del maestro, era un espacio extraño, indiferente y débil en recursos. ${ }^{16}$

Otro de los problemas resonantes de la educación rural era que los pequeños no complementaban su escolaridad demandados por los padres que los retiraban tempranamente para utilizarlos en los trabajos rurales a pesar de la ley de Obligación escolar que establecía el deber de los padres de escolarizar a sus hijos. Para ello se creó la figura del inspector de Obligación Escolar. De esta forma, el discurso educa-

15.Guzmán H. F. (1938). Una escuela rural vivida. $E M E C$, 57(782), pp. 32-43. El proceso de medicalización de los escolares comenzó a fines del siglo XIX en las escuelas de Capital Federal con la creación del Cuerpo Médico Escolar. Los médicos, como poseedores de un saber especializado, empezaron a ocupar lugares en el Estado para impulsar intervenciones públicas sobre el espacio urbano y extender, de este modo, el dispositivo institucional que intentaría mejorar el estado sanitario de la población. En este contexto se creó el Departamento Nacional de Higiene, la Administración Sanitaria, la Asistencia Pública de Buenos Aires y el Cuerpo Médico Escolar (Cammarota, 2016).

16. Sosa (1902, p. 385). tivo escolar resolvió el dilema entre la defensa de la privatización familiar de la vida infantil y el predominio del Estado con fuertes impugnaciones a las familias (Carli, 2012, p. 67).

El cumplimiento de la ley de escolaridad muchas veces se veía interceptada, no solo por los recorridos extensos que debían hacer los niños/as para llegar a las escuelas, sino también, por la desconfianza que generaba la "guarda" en el periodo escolar. Veamos el siguiente caso. En 1934 el colono de Puerto Monte Carlo (Posadas), don G. W., pidió al gobernador del Territorio, Dr. Carlos Acuña, para que interceda ante el CNE, para la creación de una escuela debido a los inconvenientes que existían en la Escuela Nacional núm. 156 de la Colonia. Él vivía en el kilómetro 20 de dicha colonia y tenía tres hijos en edad escolar: dos varones y una mujer. La escuela más próxima a su casa distaba a 7,3 km en la línea Guatambú. La topografía hacia sumamente difícil el traslado para los pequeños niños que tenían que cruzar arroyos o puentes en condiciones precarias. Por añadidura, el vecino desconfiaba del director de la Escuela a quien debía dejar "en guarda" a sus hijos en el período escolar. Las razones no son claras, sin embargo, el colono señalaba que el año anterior había denunciado al director por "razones de mi hija mayor" (sic) de 14 años de edad. A continuación, describía que como padre debía tratar por todos los medios la escolaridad de sus hijos. A ello se sumaba el hecho de que el director de la escuela en cuestión había intimado "a fuerza de intervención policial, queriéndome obligar así mandar mis hijos á la escuela de él lo que le he negado categóricamente". El colono escolarizó a sus hijos a la escuela 132 en el kilómetro 5 bajo la guarda de su hermano. Sin embargo, los niños solo podían ver a sus padres los días domingo, generando un estado de tristeza 
sumadas a las privaciones de tipo materiales. Ante esta situación, G.W puso a disposición un pequeño terreno para la construcción de una escuela, iniciativa que fue apoyada por los vecinos de la zona. ${ }^{17}$

Las memorias e informes de maestros y directores esbozaron el sentido del sacrificio y cierto empirismo que relegaba la extensa normativa para el funcionamiento de las escuelas. En diversos casos eran los maestros, emulando a los misioneros de la conquista, quienes construían "la escuela", debiendo ganar, a su vez, la confianza de las comunidades nativas. El 17 de octubre de 1905 Luis Funes fue nombrado director de la escuela del Boquete de Nahuelpán, en Chubut. Luego de una larga travesía que incluyó el barco y el ferrocarril, avanzado el invierno, y con 45 días en total de viaje; el escenario al pie de la cordillera no era lo esperado: solo el cacique tenía un rancho que se diferenciaba de los otros y que podía funcionar como escuela. La población de la comarca estaba formada por chilenos, británicos y nativos. E1 flamante director se puso manos a la obra para "construir una escuela" ya que las promesas de los indios de brindarle un espacio escolar, nunca se cumplieron. Las clases se deban al aire libre y en el patio de la casa del cacique $\mathrm{Na}^{-}$ huelpán. Los niños, que hablaban muy poco el castellano, estaban de pie. Estos, según el relato, carecen de las nociones más elementales, desconocen la gratitud y el respeto, tienen un carácter rencoroso, indolente y desconfiado. A renglón seguido:

Los indios no se toman ningún interés por la escuela; para ellos es una institución desconocida; sin utilidad, nunca han sentido sus beneficios; los pobres infelices le temen

17. Nota elevada a la Inspección Seccional de Misiones, 23 de marzo de 1935. Caja 11. FCNE. AIN. en su desconfianza, y la odian como medio que tiende, según sus creencias, a llevar sus hijos al estado de una raza que aborrecen y que en su salvaje ignorancia la creen inferior. Para el indio ¿quién es el maestro? Una huinca intrusa y nada más (...) Téngase presente que el indio es conservador por excelencia y que su educación de bárbaro, está en pugna con la que el hombre civilizado puede inculcarle (...) la bandera les trae a la mente el ejército, ese enemigo del salvaje que concluyó con su vida vagabunda. ${ }^{18}$

Como ha destacado el historiador Enrique Mases, para el caso de las comunidades nativas en el sur de la Argentina, el proceso de incorporación estuvo dado por el proceso de construcción de una sociedad capitalista y de consolidación del Estado nacional en cuanto a su autoridad y soberanía (Mases, 2002). La idea del "salvaje incivilizado" se trasladó a la pedagogía escolar acorde al credo del positivismo que permeó las bases ideológicas del proyecto de Nación.

A principios del siglo $\mathrm{XX}$, estaba muy presente el accionar militar del Estado sobre sus territorios que se vieron violentadas por la ocupación militar comenzada en 1870 del Chaco central y Austral en poder de los pueblos originarios y la denominada "Conquista del Desierto" en los territorios del sur en 1879 llevada a cabo por el general Roca. Según el maestro, la comunidad profesaba la religión católica, pero resguardaban el culto a la pacha-mama. Los niños que concurrían a la escuela eran un total de 48 de ambos sexos que debían recorrer 5 kilómetros para llegar a la escuela, por caminos accidentados y peligrosos". Semidescalzos y harapientos, la noción de "infancia" se reducía "a la tristeza,

18. Ponce, P. y Funes, L. (1906). Territorios Nacionales: cómo avanzan las primeras luces en el desierto austral. $E M E C, 10(408)$, p. 646. 
dominada por la ausencia de elementos recreativos y educativos del medio". ${ }^{19}$

La "nacionalidad" para estas comunidades podía resultar una fuerza distante, construida en los discursos de las elites dirigentes, pero cuya viscosidad alertaba sobre la finitud del alcance que tenía el Estado Nacional sobre el extenso territorio y sobre las subjetividades vernáculas que constituían el etnos de la colectividad. A su vez, la descripción del maestro chocaba de plano con la visión que tenían algunos funcionarios sobre las comunidades nativas: para el ya mencionado inspector Díaz, las comunidades indígenas ofrecían grandes ventajas como factor social por su arraigo y "amor a la tierra, sus facultades de adaptación y asimilación” (Díaz, 1907, p. 423).

El investigador Pedro Navarro Floria, ha demostrado en un estudio comparado entre Argentina, Brasil y Chile en relación con la formación de los Estados nacionales y los territorios marginales; la ineficacia de los argumentos de la raza, la lengua y la cultura como criterios para la fundación de la nacionalidad (Navarro Floria, 2008). Este análisis explica a las claras la "resistencias" de las comunidades indígenas de integrase al proceso civilizatario. Sin embargo, y a juzgar por las fuentes, la transculturación y el sometimiento de las pautas de vida tradicional, las creencias y los modos de organización a las normas del progreso, no impidió que algunas comunidades indígenas, sin tener un número específico para este estudio, solicitaran al CNE la creación instituciones escolares: hacia 1930 los vecinos de "la numerosa tribu indígena que pueblan la Pampa del Malleo, (Departamento Huiliches, Neuquén)"

19. Ponce, P. y Funes, L. (1906). Territorios Nacionales: cómo avanzan las primeras luces en el desierto austral. EMEC, 10(408), p. 647.

42 requirieron la pronta ejecución de la escuela proyectada para educar a más de ochenta niños analfabetos. En palabras de los peticionantes:

Un escuela es de capital importancia en nuestro seno, estamos seguro de que elevaría el estado cultural de la tribu campesina, ya que el maestro no solo le enseñaría las primeras letras y los primeros elementos del vivir a nuestros niños sino que sería una guía y un consejero, para guiar y encaminar mejor nuestros trabajos agrícolas pastoriles que es la fuente que nos proporciona el pan de cada día y que con la evolución y el progreso vamos quedando atrás cien años por lo menos. ${ }^{20}$

La solicitud hacía alusión a la argentinidad de la comunidad y a la vergüenza que sentirían de contribuir "con tan poco" al engrandecimiento del país "ya que la ignorancia no nos permite ir más adelante". Ya sea como entramado discursivo para obtener recursos o como un genuino sentimiento de nacionalidad, pasados casi cincuenta años del avance del Estado Nacional sobre los territorios indígenas, las críticas al proceso de nacionalización regularmente interpelaban al poder central.

Ahora bien, el CNE también mediaba en las escuelas particulares, tratando de guiar su funcionamiento acorde a las propuestas cívicas, Republicana y nacionalista del currículo. En la siguiente sección abordaremos un caso puntual que ilustra esta cuestión.

Hacia 1944, había en total en los Territorios Nacionales 51 escuelas particulares.

Un total de 298 estaban radicadas en la Capital Federal, 51 en los Territorios Nacionales y 8 en

20.Pedido de los vecinos de Pampa del Malleo. 1930.

Caja 5, Expediente 25180. FCNE.AIN. 
la Provincia de Buenos Aires. La inscripción sumaba un total de 46.522 alumnos/as distribuidos en escuelas particulares de Capital Federal, los Territorios Nacionales y la Provincia de Buenos Aires. De ese total, 39.406 asistían a escuelas de la Capital Federal, 5.527 en los Territorios Nacionales y 15.89 en instituciones de la provincia de Buenos Aires (CNE, 1944, pp. 53-54).

Desde fines del siglo XIX las comunidades extranjeras que se asentaron en el territorio nacional bregaron por educar a sus hijos en la tradición, el idioma y las costumbres de sus metrópolis. Esto suponía un obstáculo para el Estado ya que el CNE había observado la resistencia a la tendencia nacionalista de la escuela pública por parte de las escuelas particulares, laicas o religiosas como la comunidad de salesianos que se instalaron en la Patagonia y, por otro lado, la falta de efectividad en la vigilancia de los inspectores. ${ }^{21}$

Las escuelas privadas estaban regladas por la Inspección Técnica General de Escuelas Particulares quien otorgaba el permiso para el ejercicio de la docencia a particulares religiosos. Para esto se tenía en cuenta los antecedentes y las calificaciones anuales del docente. Los docentes extranjeros estaban sujetos también a este mecanismo, pero con la imposibilidad de dar clases de Historia y Geografía Argentina e

21.Los salesianos ingresaron a la Argentina en 1875. El proyecto de evangelización que sostuvieron buscaba la homogeneización cultural del indígena por medio del trabajo agrícola, el adoctrinamiento religioso y la educación en los colegios. La Congregación salesiana, alentada por Don Bosco, desplegó su proyecto educativo mediante un circuito de red de parroquias, colegios, oratorios y hospitales en la Patagonia. Ver Nicoletti (2015).
Instrucción Cívica. De acuerdo a las disposiciones generales, en todas escuelas particulares se debía inculcar el amor por la Patria y el respeto a las instituciones argentinas.

\section{Las escuelas particulares de idiomas que atentaba contra la nacionalidad}

Ante la inestable situación que presentaba el control sobre las escuelas particulares extranjeras, el 28 de septiembre de 1938 se dictó una resolución con respecto a su funcionamiento. Esta prevenía transgresiones que atentaran contra la "nacionalidad argentina": las escuelas extranjeras en las que se impartía enseñanza de idiomas debían adoptar obras exclusivamente destinadas para niños argentinos con lecturas que describan al país en su aspecto geográfico, la enseñanza de las tradiciones, leyendas, industria y comercio; lecturas comentando los grandes acontecimientos históricos (CNE, 1939, pp. 72-73).

Si bien la preocupación por las escuelas particulares desveló a los funcionarios del CNE desde los orígenes del sistema educativo argentino, durante la década de 1930, con el inicio de la denominada Década Infame iniciada con el golpe militar del general Uriburu, las corrientes nacionalistas y católicas hicieron causa común en su intento por desmantelar el Estado liberal ensamblado en el siglo XIX. $\mathrm{E} 1 \mathrm{CNE}$ se reconfiguró con funcionarios adscriptos a la ideología del nacionalismo y del catolicismo. En 1932, fue nombrado el ingeniero Octavio Pico por el presidente Agustín P. Justo (1932-1938) para hacerse cargo del CNE. Los discursos escolares profundizaron las concepciones morales, reforzaron los estereotipos de género y persecución a la alteridad 
ideológica. Bajo las dos administraciones se exoneraron a varios maestros/as, entre ellos/as, a la reconocida militante gremial e intelectual critica del magisterio Florencia Fossatti. Otros docentes fueron acusados de propagar ideologías foráneas como el marxismo (Cammarota, 2019). Entre 1930 y 1940, las corrientes nacionalistas vieron la necesidad de "erradicar" el elemento extranjero en los territorios del sur mediante la acción de la escuela, el servicio militar, el aumento de la densidad de la población, el periodismo y la acción del gobierno. Sin embargo, y a pesar de todos los esfuerzos realizados por el CNE, a comienzos de la década del cuarenta, las autoridades reconocían que la homogeneización de la población migrante en el Territorio de Santa Cruz seguían presentando una serie de escollos ya que las comunidades no modificaban sus pautas culturales (Pierini y Rotman, 2009, pp. 4-5).

Ahora bien, el siguiente caso ilumina los pormenores del problema señalado en el cual se entrecruzan la cuestión de la fiscalización sobre escuelas extranjeras y las tensiones dominantes en el espacio europeo trasladas al suelo nativo.

El 4 de abril de 1935 la escuela alemana en Colonia Santa Teresa, La Pampa, que enseñaba en idioma alemán y religión, fue clausurada por el CNE por no hallarse encuadrada dentro de la reglamentación vigente. $\mathrm{La}$ inspección General de Escuelas Particulares instó a la institución ponerse dentro de las condiciones establecidas por la reglamentación. El director de la escuela, Gustavo Kramer había elevado, equivocadamente, el permiso para el funcionamiento de la institución que debía estar legalizado por la Inspección General de Escuelas Particulares sita en la calle Rodríguez Peña 935.
En la región funcionaban cuatro escuelas idiomáticas, en las localidades de Santa María, Unánne, Villa Alba y Santa Teresa, respectivamente. Los directivos de estas instituciones, todas de nacionalidad alemana, remitieron su habilitación al CNE. El colegio de la colonia Santa María en la Pampa Central estaba a cargo de un capellán vicario, Francisco Shratzlseer, de la localidad ya que era una institución Parroquial. La escuela de Villa Alba solicitó permiso al presidente del CNE, Octavio Pico para dictar clases en alemán. El pedido fue elevado por Martin Falkenberg, nacido en Alemania, Prusia Oriental de nacionalidad ruso alemana. La demanda fue resuelta favorablemente, pero, siguiendo la normativa, con la condición de que estaba vedado para el docente dar clases de historia y geografía argentina e Instrucción Cívica.

Ante los pedidos de funcionamiento, el inspector Seccional solicitó un informe sobre el desempeño de las instituciones idiomáticas. Sobre el colegio de Unanué el informe fue muy escueto. Según el inspector actuante, no existía allí ninguna escuela particular y que en su local solo funcionaba una nacional. El informe de la escuela de Villa Alba señalaba que había tres colegios particulares idiomáticos. Uno de ellos era israelita, con una antigüedad de 20 años y que enseñaba lectura y escritura en idish y hebreo e Historia Bíblica, a cargo de un director de nacionalidad polaca quien no estaba autorizado para ejercer la docencia. Estaba sostenido por la Asociación Israelita Theodoro Hertzel y funcionaban en la sede de la Sociedad Israelita.

Otro de las instituciones era la Escuela Alemana de Religión Luterana, con una antigüedad de 16 años y dirigida por un pastor protestante, donde se enseñaba lectura y escritura e historia bíblica en idioma alemán La enseñanza estaba 
a cargo de Jacobo Hornus de nacionalidad argentina, maestro de educación religiosa cuyo título fue expedido por la Escuela Normal de la Corporación del Sínodo Evangelio Luterano.

¿Cuál era el problema que subyacía detrás del funcionamiento de estas escuelas particulares más allá de su habilitación? Es interesante ver aquí la observación realizada por un funcionario. Según el informe presentado entre los inconvenientes estaba la afectación de la Escuela núm. 16 de carácter público y la enseñanza del idioma extranjero a niños que provienen de hogares extranjeros, por profesores extranjeros que desconocen el idioma nacional e impiden a los niños/as que escriban y hablen correctamente el castellano. Por añadidura, se sumaba el desconocimiento por parte de los docentes de las leyes, costumbres e instituciones nacionales y la falta de idoneidad que atentaba "contra la orientación nacionalista de la escuela pública”. A renglón seguido, el funcionario argüía:

Los niños que concurren a las escuelas particulares idiomáticas, vinculados por el común origen de sus padres, las costumbres de hogar, los lazos de familia y el del propio idioma extranjero, crean intereses entre sí que no coinciden con los de los demás niños argentinos, $y$ hasta ofrecen el inconveniente de fomentar malquerencia y hostilidad entre elementos de colectividades diferentes. ${ }^{22}$

Desde su óptica, muchos de los desvíos, y deficiencias de las escuelas locales particulares se debía a la falta de fiscalización y control oficial, un problema que, como hemos destacado a principios de este apartado, se repetía regu-

22.Informe del inspector seccional, 5 de mayo de 1935. Caja 11 Expediente 16970. FCNE. AIN. larmente en los informes de los funcionarios y publicaciones del CNE. Allí también podían actuar intereses extraños y hasta contrarios a los fundamentos de la sociedad argentina. En esta dirección el funcionario destacaba que hacía dos años que la colectividad alemana de Villa Alba, estimulada por instituciones de esa nacionalidad de la Capital Federal, "despertó a una vida de gran actividad”. Se habían nombrado comisiones directivas, se organizaron actos públicos y festivales, se exhibieron cintas cinematográficas de la Nueva Alemania, se pronunciaron discursos encendidos en idioma alemán y se puso en práctica el saludo fascista. Las actividades fueron de política- racial o "nacional-nazistas" (sic). Esta escenificación generó rispideces con la comunidad judía ya que, según el informe del inspector, se pintó la cruz esvástica en las paredes públicas con agresiva intención. ${ }^{23}$

Luego de un año parecía que los ánimos se habían apaciguado, constituyéndose una "Asociación Escolar Alemana”, local y autónoma prescindiendo de toda orientación racial. La posición del Inspector se veía fundamentada luego de que el gobernador del Territorio formulara una denuncia en el Ministerio de Justicia e Instrucción Pública de la Nación por infiltración extranjera en las escuelas particulares de la Pampa.

El colegio de Santa María no era solo una excepcionalidad en las preocupaciones formativas de los funcionarios del CNE. Otra de las instituciones en cuestión fue la radicada en Santa Teresa, también de origen alemán. Su director, Tomas Kopp, era de nacionalidad alemana y hacía tres años que residía a en el país.

23.Funcionamiento de Escuelas Idiomáticas en Villa Alba, 5 de mayo 1935. 5. Caja 11 Expediente 16970. FCNE. AIN. 
Era sostenida económicamente por la contribución de los vecinos quienes se nucleaban en la Sociedad Escolar Alemana, patrocinada por la Deutscher Kulturrat (Cultura Alemana), dependiente de la embajada germana. Hasta entonces, el director no tenía autorización oficial para el funcionamiento. El 4 de abril de 1938 fue clausurada la institución por la policía departamental.

Según el informe del inspector, uno de los salones disponía en la pared de un crucifico, un retrato de San Martín a 4 colores 0.45 x 0.35 y, subrayado en rojo en el informe, un retrato de Hitler. También sobresalía un mapa hidrográfico de Sud-América y tres láminas con vistas de Alemania y una imagen de Hindenburg.

El inspector actuante no escatimó esfuerzos en solapar su asombro. El escenario descripto se debía a los colonos que llegaron a poblar los campos argentinos

Nunca han sentido amor a la tierra ni han comprendido el alcance de nuestras leyes ni la esencia de nuestras instituciones. Tienen en el fondo de su ser algo del pueblo nómade (...) La mayoría de los viejos pobladores son analfabetos y por lo tanto fácil rebaño para conducirlos (...) toman ciegamente estas ideas; alemanes por tradición, desconocen su verdadera nacionalidad y asíllegan a sentirse en verdaderos nazistas alemanes y profundamente católicos romanos, sin comprender ninguno de los dos ideales que sustentan. ${ }^{24}$

Por lo visto, a las autoridades del CNE poco les importaba el retrato de Hitler. En 1935, Hitler podía ser pensado como un dictador más en el

24. Funcionamiento de Escuela idiomática Santa Teresa. 6 de mayo 1935. Caja 11 Expediente 16970. FCNE.

AIN. escenario político de Europa con un discurso racial y antisemita que lograba despertar simpatías en los grupos nacionalistas más reaccionarios vernáculos por su antisemitismo y su anticomunismo. Lo cierto es que el funcionamiento de las escuelas alemanas, como hemos visto en el informe del inspector, lesionaba el ideal de nacionalidad deseable instruido en las escuelas bajo el control del CNE.

El caso se cerró como se preveía: la resolución del CNE, del 10 de julio de 1939, con respecto a las escuelas idioma y religión de La Pampa fue la siguiente: la escuela de Santa Teresa, la escuela de la colonia Santa María y la escuela luterana de Guatraché debían ponerse a tono con la reglamentación vigente, mientras que la de Villa Alba, a cargo del maestro Martín Falkenberg, quedaba legalmente autorizada para funcionar.

E1 caso de las escuelas idiomáticas era una de las excusas para la declamación del nacionalismo que le daban asidero a la denuncia de intelectuales como Ricardo Rojas, quien reclamaba un modelo arraigado en las tradiciones y un espíritu nacional. Desde fines del siglo XIX, pero sobre todo a partir de los festejos del Centenario en 1910, primó en las elites dirigentes una concepción cultural esencialista de la nación que expulsó al cosmopolitismo y denostó los anclajes culturales e idiomáticos de las comunidades extranjeras asentadas en el territorio. Cuanto más heterogénea fue la población, producto de la inmigración, mayor fuerza cobró el modelo basado en la homogeneidad y la invariabilidad (Bertoni, 2001, p. 316). La escuela no estuvo exenta de este proceso. Al contrario: marcó rumbos de acción intentando legitimar cierta pureza de un ideal patriótico, cívico y nacionalista. 


\section{Conclusiones}

La conformación del sistema escolar en base a la Ley de Educación Común (1420) y su extensión sobre el territorio del país consumó las intenciones de las elites dirigentes por erradicar el analfabetismo y forjar al futuro ciudadano republicano. También propendió al afianzamiento de los valores nacionalistas, la homogeneización de las comunidades indígenas y la salvaguarda de la soberanía territorial. Para ello, el CNE estructuró la Inspección de Escuelas Primarias en los Territorios y Colonias Federales a cargo de Raúl Díaz cuyo desempeño sentó las bases para la extensión de los servicios educativos.

La gesta educativa no se circunscribió a la asunción de determinados postulados emanados de la repartición central ya que las limitaciones materiales eran palpables. No obstante, el activismo societario, expresado en la donación de terrenos o edificios, el relevamiento de la población escolar, el abastecimiento de útiles o mobiliario y las relaciones entre vecinos y funcionarios escolares; imprimieron a las claras una trama mucho más compleja que ilumina, en todo el proceso histórico abarcado, lo discontinuo que resultaba sostener la escolarización de niños y niñas en los Territorios Nacionales.

En líneas generales, la ausencia de caminos aptos para su tránsito, la ausencia de estadísticas fiables tabuladas de manera científica en la que intervenían diversos actores como inspectores, vecinos y registros civiles; la idiosincrasia de las comunidades locales y la precariedad de muchos de los locales escolares, eran parte de una habitualidad que en muchos casos excedía las predicciones y aspiraciones de la burocracia educativa. A ello se agregaba la improvisación pedagógica con maestros/as sin títulos habilitantes o el empirismo de los más comprometidos con la causa educativa.

Este artículo nos permite conjeturar sobre el funcionamiento y el radio de influencia de la escuela en las primeras cuatro décadas del siglo XX. Matizamos la idea de una primacía de uno delos dos paradigmas que nucleó el espacio escolar, entre el modelo socializador o el utilitario. Entendemos que la trama es mucho más porosa y dependió de las particularidades, los recursos y los alcances de las políticas educativas en cada localidad. Consideramos que faltan aún investigaciones regionales que asuman, desde el campo de las políticas sociales, la relación entre el poder central, los Territorios, las provincias y la sociedad civil como destinataria de esas políticas. El análisis propuesto posibilita escudriñar determinados condicionantes sobre los cuales se implementó la instrucción y la educación primaria en nuestro país, en torno a un imaginario común cuyo mandato era la homogenización de los habitantes de una nación que se percibía en construcción en las primeras décadas del siglo XX.

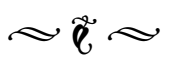




\section{Referencias Bibliográficas}

Ascolani, A. (2012). La escuela primaria rural en la Argentina. Expansión, orientación y dificultades (19161932). Revista Teias, 14(28), 309-324. Recuperado de https:/www.e-publicacoes.uerj.br/index.php/ revistateias/article/view/24245/17224

Bertoni, A. L. (2001). Patriotas, cosmopolititas y nacionalistas. La construcción de la nacionalidad argentina a fines del siglo XIX. Buenos Aires: Fondo de Cultura Económica.

Billorou, M. J (2011). La labor de la Comisión Nacional de Ayuda Escolar (1938-1943): encarar la acción en su verdadero concepto de imperativo social. En I. Cosse, V. LLobet, C. Villalta, M. C. Zapiola (Eds.), Infancias: politicas y saberes en Argentina y Brasil, siglos XIX y XX. (207-233). Buenos Aires: Teseo.

Billorou, M. J (2015). Los niños de escuela rural: educación e infancia en el Territorio Nacional de la Pampa en la primera mitad del siglo XX. Ponencia presentada en IV Jornadas de Estudios sobre la Infancia, Buenos Aires, Argentina.

Bucciarelli, M.y Jensen, S. (2008). La historiografía de los Territorios Nacionales: un campo en construcción. Anuario del Centro de Estudios Historiográfico "Profesor Carlos Segreti", 8(8), 183-200.

Cammarota, A. (2016). Saberes médicos y medicalización en el ámbito escolar (1920-1940). Pilquen, 19(3), 33-51.

Cammarota, A. (2019). El caso de los maestros comunistas y el Diario Crítica (1933-1940). Revista Pilquen, Sección Ciencias Sociales, 22(1), 1-12.

Carli, S. (2012). Niñez, pedagogía y politica. Transformaciones de los discursos acerca de la infancia en la bistoria de la educación argentina 1880-1955. Buenos Aires: Miño y Dávila.

Consejo Nacional de Educación (1938). Cincuentenario de la Ley 1420. Memoria sobre el desarrollo de las escuelas primarias desde 1884 a 1934. Tomo II. Buenos Aires: Consejo Nacional de Educación.

Consejo Nacional de Educación (1942). Cincuentenario de la Ley 1420 Edificación escolar en Territorios Nacionales y provincias (Ley 4874). Tomo III. Buenos Aires: Consejo Nacional de Educación.

Consejo Nacional de Educación (1944). Educación Común en la Capital, Provincias y Territorios Nacionales. Informe presentado al Ministerio de Justicia e Instrucción Pública por el Consejo Nacional de Educación. Buenos Aires: Consejo Nacional de Educación.

Di Liscia, M. S. (2009). Cifras y problemas. Las estadísticas y la salud en los Territorios Nacionales (18801940)”. Salud Colectiva,5(2), 259-278.

Fiorucci, F. (2015). Raúl B. Díaz: el inspector de Territorios Nacionales. Miradas, recorridos y reclamos de un funcionario viajero (1890-1916). Anuario de Historia de la Educación Argentina, 16(2), 82-92. 
Fiorucci, F. (2011) Las escuelas normales y la vida cultural en el interior: apuntes para su historia. En: P. Laguarda y F. Fiorucci (Ed.), Intelectuales, cultura politica y espacios regionales (pp. 131-152). Rosario: Prohistoria.

Fiorucci, F. (2016). País afeminado, proletario feminista. Mujeres inmorales e incapaces: la feminización del magisterio en disputa (1900-1920). Anuario de Historia de la Educación, 17(2), 120-137.

Liga Nacional de Educación (1914). Estatutos aprobados en Asamblea el 7 de noviembre de 1913. Buenos Aires: Liga Nacional de Educación.

Lionetti, L. (2005). La función republicana de la escuela pública: la formación del ciudadano en Argentina a fines del siglo XIX. Revista Mexicana de investigación educativa, 10(27), 1225-1255.

Mases. E. (2002). Estado y cuestión indígena: el destino final de los indios sometidos en el sur del territorio (18781930). Buenos Aires: Prometeo.

Meneclier, J. (1920). Estudio sobre la población escolar de la República. 1914-1920. Buenos Aires, Argentina: Consejo Nacional de Educación.

Nari, M. (2004). Politicas de maternidad y maternalismo politico. Buenos Aires, 1890-1940. Buenos Aires: Biblos.

Navarro Floria, P. (2008). La construction des territoires nationaux latino-americains vue depuis leurs marges. Amérique Latine Histoire et Mémoire). Cabiers ALHIM, 4(16) 167-180. Recuperado de https:// journals.openedition.org/alhim/3112?lang=en\#text .

Nicoletti, M. A. (2015). La Congregación salesiana en la Patagonia: “civilizar”, educar y evangelizar a los indígenas (1880-1934). Estudios Interdisciplinarios de América Latina y el Caribe,15(2).

Pierini M. y Rotman, S. (2009). La escuela como presencia del Estado Central en el Territorio Nacional de Santa Cruz. Ponencia presentada en XII Jornadas Interescuelas de Historia, San Carlos de Bariloche, Argentina.

Ruffini, M. (2004). Ciudadanía y Territorios Nacionales. El ejercicio del poder político en los Concejos Municipales del Territorio Nacional de Río Negro 1886- 1908. Revista Escuela de Historia, 1(43), 43-62. Recuperando de http://biblioteca.clacso.edu.ar/Argentina/cehepyc-uncoma/20110419113601/ salta.pdf

Salvatore, R. (2016). Burocracias expertas y exitosas en Argentina: Los casos de educación primaria y salud pública (1870-1930). Estudios Sociales del Estado, 2(3), 23-64.

Soto Arango, D. E. (2012). La ruralidad en la cotidianidad escolar colombiana. Historia de vida de la maestra rural boyacense. 1948-1974. Revista Historia de la Educación Latinoamericana, 14(18), 211243. Recuperado de https://revistas.uptc.edu.co/index.php/historia_educacion_latinamerican/article/ view/1621. 
Teobaldo, M. (2011) ¡Buenos dias, Sr. Inspector! Historia de los inspectores escolares en la Patagonia Norte: Rio Negro y Neuquén. Perfil y funciones (1884-1962). Córdoba: Editorial de la Facultad de Filosofía y Humanidades.

Varela, M. (2015). Estado y Territorios Nacionales. Relaciones, tensiones y conflictos en la sociedad y la politica rionegrina (1916-1943) (Tesis doctoral inédita). Universidad Nacional de La Plata, La Plata, Argentina. Recuperado de http://www.memoria.fahce.unlp.edu.ar/tesis/te.1175/te.1175.pdf.

Vaughan, M. K. (2001). La política cultural en la Revolución. Maestros, campesinos y escuelas en México, 19301940. México: Fondo de Cultura Económica.

Zaidenwerg, Cielo (2013). La 'Argentinización' de los Territorios Nacionales a través de la educación formal e informal. Estudio de caso Rio Negro (1908-1930) (Tesis doctoral inédita). Universidad de Barcelona, Barcelona, España. Recuperado de https://www.tdx.cat/bitstream/handle/10803/117074/Zaidenwerg tesis.pdf? sequence $=18$ is Allowed $=y$ 